\title{
Meditation for Increased Mindfulness and Memory: An Analysis on the Impact of Meditation on Mindfulness and Working Memory Capacity in High School Students
}

\author{
Rebeccah Fleischmann ${ }^{1}$ and Michael Posner ${ }^{1}$
}

${ }^{1}$ Conrad High School, West Hartford, CT, USA

\section{ABSTRACT}

Zero percent of high school students see anxiety and depression as a "major problem" among their peers (Pew Research Center). Meditation decreases anxiety and stress according to Harvard researchers. Stress and memory are very much connected as a recent study concluded that non-stressed people remember more items on average than stressed people. Although several studies have been done on the impacts of meditation, there has been no research done specifically on the impact of meditation on high school students' working memory. This study utilized a prepost survey design and a running control group to determine whether mindfulness and working memory capacity increased as a result of a week of daily meditation. Students were randomly assigned to the mindfulness meditation group or to the running control group. Both groups took The Human Benchmark memory test and the Mindfulness Attention Awareness Scale (a Likert scale) before and after a week of meditation or running. The results proved to be significant, showing that mindfulness increased on average by .8 points, while the control only increased by .03 points on average. In addition, memory test scores increased by $40.3 \%$ for the meditation group compared to $8.3 \%$ for the control group.

\section{Introduction}

Meditation has existed since the Vedas around $1500 \mathrm{BCE}$ and remains a vital part of daily life in several cultures (Wynne, 2007). Meditation is a mind and body practice that has been shown to increase calmness and enhance overall well-being (Sedlmeier, 2012). Meditation can be done in a variety of ways, through focusing on one's breath or repeating a mantra. Mindfulness is a state of consciousness attained through one's meditation practice. According to the American Psychological Association (Davis, 2012), mindfulness is: “...a moment-to-moment awareness of one’s experience without judgment."

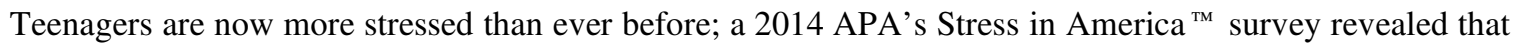
teen stress rivals that of adults. A recent study from the international science journal, BMJ Open, conducted by the Finnish Institute for Health and Welfare found a correlation between stress and lifespan: the more one stresses, the 
shorter their lifespan (Härkänen, 2020). Meditation improves emotion regulation, and lessens stress responses according to Harvard researchers (Sevinc, 2019). Therefore, meditation helps us live longer and is especially beneficial for the age group who stress the most: teenagers. In addition to living longer, there are numerous other positive impacts on teens, especially on their brains. Several studies have been done on the impacts of meditation on teens, such as the study conducted by Dianna Quach (2016), professor of psychology at Alliant International University, which found that meditation improved memory in middle schools (Biegel, 2009; Greenberg, 2019; Quach, 2016). However, there has been no research done specifically on the impact of meditation on high school students' working memory.

\section{Literature Review}

In addition to decreasing stress and anxiety, a common goal of many is to find happiness in one's life. While happiness is partially determined by factors such as our genes and our evolution, 50 percent of happiness is within our control (Lyubomirsky, 2005). Psychologist William James puts it as "If you can change your mind, you can change your life" (Taylor, 2011). The secret to happiness is as simple as becoming more mindful. Richard Davidson (2003), Professor of Psychology at the University of Wisconsin, found in his research that meditation redistributes the balance between the left and right frontal areas, sparking more left-brain activity and thus positive emotion. High levels of activity in the left frontal area of the cerebral cortex occurred at the same time with feelings of joy, enthusiasm, happiness, alertness, and high energy. Moreover, high levels of activity in the right frontal area coincided with feelings of sadness and anxiety.

M. Ramesh (2013), Professor of Physiology at Melaka Manipal Medical College, conducted a study on the effect of Brahma Kumaris Rajayoga Meditation (BKRM) on positive thinking. The study from the peer-reviewed publication, The Journal of Clinical and Diagnostic Research, compared two groups, meditators, and non-meditators, doing BKRM, a type of breathing meditation. The researchers administered the Oxford happiness questionnaire to subjects. Ultimately, they found that BKRM significantly promotes self-satisfaction and happiness in life by increasing positive thoughts notwithstanding of age and experience in one's meditation practice. A similar perspective is found in a study by Daniel Campos (2016), Professor of Psychology at Jaume I University. He examined the relationship between mindfulness skills formed by meditation and happiness. Almost 400 participants took the Self-Compassion Scale-short form (SCS), the Five Facets of Mindfulness Questionnaire (FFMQ), and the Pemberton Happiness Index. He utilized hierarchical regression analysis to determine which particular traits correlated the most with one's measured happiness score. This analysis revealed that two FFMQ components (Observing and Awareness) and two SCS facets (Self-kindness and Common humanity) were statistically significant predictors of happiness. The researchers also found that mindfulness and self-compassion qualities that result from a daily meditation practice are the bridge that connects meditation and happiness.

Anat Shoshani (2013), Professor of Psychology at IDC Herzliya College, highlights the need for a program to help middle school students feel happier. Shoshani discusses how the transition to middle school is very difficult for adolescents, which is evident in their low happiness ratings. A viable solution to improving middle school students' happiness was examined in a study by David Viafora (2015), Professor of Social Work at San Diego State University. He found that many middle school students enrolled in an 8-week meditation course reported feeling less stress and had increased resilience and positive risk-taking. 
In another study on the impacts of meditation on students, forty-five African American teenagers were randomly assigned to either a health education group or Transcendental Meditation (TM) group. Dr. Barnes (2003), a professor of psychology at the Georgia Institute for Prevention of Human Diseases and Accidents, Medical College of Georgia, an expert in the field of behavior, led this study. For four months, the TM group meditated for 15 minutes at home and school, while the health education control group engaged in 15-min sessions of health education at school. Students who participated in the TM program missed fewer days of school, had reduced rule infractions and suspensions compared to the control group. This study also found that students were less stressed, meditation decreased negative behavior, and corroborates the previous study.

Another randomized clinical trial was created to examine the impact of the mindfulness-based stress reduction (MBSR) program for 102 high school students with several diagnoses in a psychiatric facility. Dr. Gina M. Biegel and Shauna L. Shapiro (2009), the researchers, are experts in the field of psychology. Compared to control participants who received care as usual at the facility, those in the MBSR program reported fewer symptoms of anxiety, depression, and somatic distress, and improved self-esteem and sleep quality. Additionally, over the 5-month study period, the MBSR group revealed a greater percentage of diagnostic improvement and significant gains in the global assessment of functioning scores relative to controls. This study furthered the work of Barnes (2003) by finding that anxiety and depression were lessened and self-esteem increased.

Building off of the aforementioned study, the authors of A school-based mindfulness pilot study for ethnically diverse at-risk adolescents designed a randomized pilot study of a school-based mindfulness program called Learning to BREATHE with a diverse population of at-risk adolescents. Karen Bluth (2015), the lead researcher of this study, is a professor of psychiatry at the University of North Carolina at Chapel Hill and is a certified instructor of mindfulness. Twenty-seven students participated in either a mindfulness course or a substance abuse control class for 50 minutes, once a week, for half of a school year. Students found that the mindfulness class alleviated their stress and lessened their depression and they favored continuing the class.

A randomized controlled study published in Developmental Psychology explored the impacts of a 12-week mindfulness-based Kindness Curriculum (KC) on 68 preschool children. The lead researcher of this study was Simon B. Goldberg (2015), a professor of psychology at the University of Wisconsin-Madison and an expert in the field of mindfulness. The $\mathrm{KC}$ intervention children revealed significant improvement in their social skills and grades in school compared with their control group counterparts. Researchers discovered that the mindfulness program had a direct positive impact on the preschoolers' health, ability to learn, and cognitive flexibility in contrast to the control group. Moreover, the $\mathrm{KC}$ preschoolers who initially scored lower in social abilities and executive functioning surprisingly showed the greatest improvements in social skills compared to the control group. Although research on meditation shows that it helps learning, health, and emotional development, there is a gap in researching meditation's impact on mental development.

Prior research illustrates that meditation may be well suited to reduce anxiety and promote social skills. A study conducted by Jay Beauchemin (2008), professor of medicine at the University of New England, and his team utilized pre and post surveys to look into the feasibility of, feelings toward, and outcomes of a 5-week mindfulness meditation intervention. This study's sample consisted of 34 adolescents dealing with a learning disability. Post survey responses revealed positive feelings toward the program. All survey results showed significant improvement. Participants who finished the program showed decreased anxiety, greater social skills, and improved academic performance. 
In addition to helping some social and behavioral aspects of high school students' lives, research has recently illuminated meditation's positive effects on one's health. Dr. James E. Stahl (2015) and his group of Harvard researchers examined an eight-week mind-body program provided through the Benson-Henry Institute for Mind Body Medicine at Massachusetts General Hospital. For the duration of the program, participants were taught meditation, yoga, mindfulness, cognitive behavioral skills, positive psychology, and various other mind-body approaches. At the hospital, the researchers held meditation sessions each week, and participants were asked to continue the practice at home. Program participants used $43 \%$ fewer medical services than they had in the prior year. Consequently, each participant saved about $\$ 2,400$ per year in emergency room costs. The researchers concluded that mind-body programs have the potential to help each participant save health care costs from $\$ 640$ to $\$ 25,500$ each year. This study sheds light on how meditation programs could translate into thousands of dollars saved each year by providing immense health benefits to participants.

Another example of how meditation can improve one's health is shown in a study conducted by the aforementioned Dr. Barnes (2001). This study investigated the effects of Transcendental Meditation (TM) on cardiovascular reactivity in high school students with high normal blood pressure. Thirty-five teenagers were randomly placed in the TM group or the health education control group. In the TM group, students meditated for 15 minutes twice each day for two months. Researchers found that the TM program had a favorable impact on cardiovascular functioning at rest as well as during acute laboratory stress in high school students at-risk for hypertension. This beneficial impact on the heart for TM program participants was likely due to larger decreases in resting blood pressure in addition to other various improvements compared to the control group.

As this study by Barnes (2001) reveals that meditation has advantageous effects on one's heart or more broadly on one's health as a whole, these positive consequences on one's health led the researcher to question what impact meditation has on the brain. The author of a study on this topic is Richard J. Davidson (2012), a renowned professor of psychology and psychiatry at the University of Wisconsin-Madison and the chair of the Center for Healthy Minds, which researches well-being and mental health. His article on the current neuroscience research on meditation found several positive effects, including improved social skills related to emotion, attention, empathy, and compassion. He found that a consistent meditation practice creates plastic changes in brain function and structure, promoting social behavior and academic success in adolescents.

In another study contributing to the existing body of cognitive neuroscience research, Sara Lazar (2005) and her team at Harvard found that eight weeks of Mindfulness-Based Stress Reduction (MBSR) transforms the structure of the brain. This mindfulness meditation program thickens the hippocampus, the part of the brain which regulates memory and learning processes. Also, MBSR enlarged areas of the brain that are involved in emotion regulation and self-referential processing. It also decreased cell volume in the amygdala, which processes emotions of fear, anxiety, and stress. Both of these structural transformations correlated with the lowered stress levels of participants. This groundbreaking research uncovered that mindfulness meditation both changes the structure of the brain and impacts our subjective perception and feelings.

In a different randomized controlled study regarding the impact of mindfulness meditation on the brain, researchers examined whether a two-week mindfulness-training course would reduce distracting thoughts and boost cognitive performance. Michael D. Mrazek (2013) and his team of researchers who conducted this study are professors at the University of California Santa Barbara. Furthermore, this source was a peer-reviewed journal, published in the 
well-known journal Psychological Science. Mrazek and his team examined a population of college students taking the Graduate Record Examination (GRE) and wondered if mindfulness meditation could improve their scores on the GRE test by aiding their memory and helping students to have a clearer mind. The researchers discovered that mindfulness training increased both working memory capacity and GRE reading-comprehension scores (on average by 16\%). Moreover, at the same time, mindfulness training decreased the amount of distracting thoughts experienced during the completion of the GRE, allowing students to completely focus on the task at hand. Overall, the researchers found that college students performed better on the GRE by practicing mindfulness and added to the body of meditation research that mindfulness increases cognitive function.

In another study, researchers investigated the efficacy of a mindfulness meditation intervention on improving working memory capacity (WMC) in adolescents. In this randomized controlled trial, researchers compared a mindfulness meditation group to a hatha yoga group and a waitlist control group. Dianna Quach (2016), the main researcher, is a professor of Professional Psychology at Alliant International University in San Diego, California. Quach is an expert in the field of psychology with decades of experience in research. This source was a peer-reviewed journal, published in a well-known journal Journal of Adolescent Health. To conduct the study, one hundred and ninety-eight middle school students from a large public middle school in the southwest United States were randomly assigned to one of the three groups of mindfulness meditation, hatha yoga, or a waitlist control condition. Before and after the intervention, participants completed a computerized measure of WMC (Automated Operational Span Task) and selfreport assessments of perceived anxiety (Screen for Childhood Anxiety Related Emotional Disorders) and stress (Perceived Stress Scale). Researchers discovered that meditation increased the working memory capacity in middle school students. This was the first study to provide support for the benefits of a mindfulness practice that was completed in a short time in improving WMC in adolescents. Although research has been done on how meditation improves behavior, health, happiness in all age groups, and how it improves memory in middle school students, there has been nothing done on how meditation impacts working memory in high school students. Reviewing the current research led to the research question: To what extent does a week of daily mindfulness meditation improve the working memory and mindfulness of teens in a Connecticut high school? The researcher hypothesized that a week of daily meditation would increase both the working memory and mindfulness of Connecticut high school students.

\section{Methodology}

After reviewing the literature, it became evident there was a gap in the field regarding the impact of mindfulness meditation on the working memory of high school students. The gap in the body of meditation research is addressed in this study by surveying high schoolers' mindfulness and testing their working memory before and after a week of mindfulness meditation and running in a high school in Hartford County, Connecticut. After completing the research and obtaining data, administrators in the selected school were informed of the results for them to consider implementing a mindfulness meditation program. The study was inspired by several studies in which people's working memory was assessed before and after meditation (Van Vugt, 2011; Quach, 2016; Buttle, 2011). I used these studies because they were validated, but I had to tailor my research to the high school population and thus, created an original method for this study. 


\section{Participants}

A school in Hartford county was selected under careful consideration due to its proximity to the researcher and the ability to reach a large sample size that is representative of the student population in the local region. For research participation, the high school required that the name of the school and the identities of the participants be kept confidential. The population examined in the study were students from the ninth, tenth, eleventh, and twelfth grades.

\section{Mindfulness Survey}

A mindfulness survey was sent out to the whole school using a Google Form and was administered to high school students during the school day. The Mindful Attention Awareness Scale (MAAS) was utilized, which asks fifteen specific questions to assess mindfulness, such as "I find myself doing things without paying attention." The MAAS asks participants to rate each question on a six-point Likert scale, labeled as: almost always, very frequently, somewhat frequently, somewhat infrequently, very infrequently, or almost never (Brown \& Ryan, 2003). To take into account "socially desirable responding," participants are requested to answer based on what "really reflects" their experience instead of what they believe their experience should be. The questions range in a variety of domains including cognitive, emotional, physical, interpersonal, and general ones. The first seven questions assess the ability of the individual to be aware of their surroundings, through asking questions, such as "I tend not to notice feelings of physical tension or discomfort until they really grab my attention." The second group of eight questions determines to what extent are the participants conscious of their actions in the present moment, rather than focusing on their emotions about the past and future, such as "I find myself preoccupied with the future or the past" and "I do jobs or tasks automatically, without being aware of what I'm doing."

The MAAS was chosen for multiple reasons. First, the survey quantifies mindfulness, allowing the researcher to compare and interpret the data with ease. Moreover, researchers have tested its validity, and according to Drs. Kirk Brown \& Richard Ryan, the MAAS was found to have good internal consistency, with an alpha of .82 in student samples, which reveals its high reliability (Brown \& Ryan, 2003). It was found to be "one of the most effective methods of assessing mindfulness in adolescents" (MacKillop \& Anderson, 2007). Lastly, due to its short length of only 15 questions, participants can fill it out easily. The research subjects completed the MAAS before and after a week of daily mindfulness meditation. The MAAS can be found in Appendix A.

\section{Memory Test}

Students took a memory test before and after the meditation intervention to determine if their working memory changed as a result of meditation. The researcher found several credible and reliable instruments to measure memory, such as the Automated Operation Span Task (AOSPAN), which was utilized in previous studies (Greenberg, 2019; Quach, 2016). In a recent study by Jonathan Greenberg (2019), professor at the University of California Berkeley, and his team, participants were asked to begin by taking a memory test. First, each participant watched as a group of letters flashed on a computer screen. Then, the screen went blank for a few seconds. Following the blank screen, participants 
were shown a single letter and probed to identify if they had seen that letter before. A memory test is essential to this experiment as it quantifies memory, which can be then utilized to compare each participant's mindfulness score with and determine if there is a correlation between mindfulness meditation and one's working memory capacity. A limitation to the research for the memory evaluation was that after contacting several professors and authors of the aforementioned memory test, the researcher was unable to obtain a usable copy of the memory evaluation. In lieu of using AOSPAN, the researcher utilized the "Human Benchmark Test" specifically, its Verbal Memory Test to accomplish the same purpose. This memory test shows the participant one word at a time, such as "grandeurs," and prompts them to determine if they have or have not seen it before during the test on the screen. Similar to the aforementioned study by Greenberg (2019), this study relies on a credible method of measuring how many words one can keep in short term memory at once. The Human Benchmark Verbal Memory Test was also chosen because of its proven reliability and validity in past experiments examining the impact of meditation on adults' short term memory (Butola \& Chauhan, 2014; Tenney, 2006).

\section{Control Group}

Participants were randomly assigned to the experimental group or the control group in order to increase confidence in the validity of the results. Both groups were measured utilizing the same mindfulness survey and memory test before and after a week of their respective activity. The control group participants ran on their own for 10 minutes a day and communicated with the researcher each day through text, email, or in-person to confirm their participation. No particular speed, distance, or incline was specified to the participants; they were only required to keep track of their time. Participants ran every day for seven consecutive days, which was the same duration assigned for the meditation group.

\section{Mindfulness Meditation Practice}

Meditation group participants followed their breath with a meditation YouTube video created by Diana Winston, Professor at the UCLA Mindful Awareness Research Center. This video has been utilized in several studies conducted by the UCLA research group and researchers on a global scale (Zylowska, 2008; Flook, 2010). Participants watched this five-minute video for seven consecutive days and each person checked in with the researcher every day through text, email, or in-person to confirm their participation. In order to practice proper meditation, Professor Zylowska (2008) directed participants to maintain good posture during their meditation practice, in a quiet and distraction-free place. The researcher also had participants follow these same instructions. Flook (2010) mentioned the importance of having a consistent time for meditation each day. The time of day does not matter, as long as participants stay consistent in their meditation practice. Participants were instructed to meditate at the time they felt most comfortable. For example, some participants meditated right before bed, while others did so before school. Prior to a week of meditation, participants completed the pre mindfulness survey and pre memory test. Directly following a week of meditation, they completed the post mindfulness survey and post memory test. 


\section{Results and Analysis}

Before and after a week of meditation, in addition to the memory test, participants in the meditation group filled out a Google Forms survey that analyzed their mindfulness. Additionally, the running control group completed the same assessments before and after running each day for 10 minutes. Averages were determined for each item and then, a total average of mindfulness was found from these initial averages. According to Table 1, the overall pretest mindfulness average was found to be 3.5 and the overall post-test mindfulness average was found to be 4.0. The net increase in mindfulness as a result of a week of daily mindfulness meditation was .5. Therefore, results reveal that mindfulness meditation does increase one's mindfulness score.

Table 1: Overall Averages and Net Increase In Mindfulness for Each Survey Item for Meditation Group

\begin{tabular}{|c|c|c|c|}
\hline Item & Pretest Average & $\begin{array}{l}\text { Posttest Aver- } \\
\text { age }\end{array}$ & Net Increase \\
\hline $\begin{array}{l}\text { I could be experiencing some emotion and not be con- } \\
\text { scious of it until sometime later. }\end{array}$ & 3.6 & 3.9 & 0.4 \\
\hline $\begin{array}{l}\text { I break or spill things because of carelessness, not paying } \\
\text { attention, or thinking of something else. }\end{array}$ & 4.0 & 4.5 & 0.4 \\
\hline $\begin{array}{l}\text { I find it difficult to stay focused on what's happening in } \\
\text { the present. }\end{array}$ & 3.3 & 3.8 & 0.5 \\
\hline $\begin{array}{l}\text { I tend to walk quickly to get where I'm going without } \\
\text { paying attention to what I experience along the way. }\end{array}$ & 3.4 & 3.6 & 0.3 \\
\hline $\begin{array}{l}\text { I tend not to notice feelings of physical tension or discom- } \\
\text { fort until they really grab my attention. }\end{array}$ & 3.7 & 4.0 & 0.3 \\
\hline $\begin{array}{l}\text { I forget a person's name almost as soon as I've been told } \\
\text { it for the first time. }\end{array}$ & 3.3 & 3.7 & 0.5 \\
\hline $\begin{array}{c}\text { It seems I am "running on automatic," without much } \\
\text { awareness of what I'm doing. }\end{array}$ & 3.5 & 4.3 & 0.7 \\
\hline $\begin{array}{l}\text { I rush through activities without being really attentive to } \\
\text { them. }\end{array}$ & 3.5 & 4.1 & 0.5 \\
\hline $\begin{array}{l}\text { I get so focused on the goal I want to achieve that I lose } \\
\text { touch with what I'm doing right now to get there. }\end{array}$ & 3.5 & 4.3 & 0.8 \\
\hline $\begin{array}{l}\text { I do jobs or tasks automatically, without being aware of } \\
\text { what I'm doing. }\end{array}$ & 4 & 4.3 & 0.3 \\
\hline $\begin{array}{l}\text { I find myself listening to someone with one ear, doing } \\
\text { something else at the same time. }\end{array}$ & 3.1 & 3.9 & 0.8 \\
\hline
\end{tabular}




\begin{tabular}{|c|c|c|c|}
\hline $\begin{array}{c}\text { I drive places on 'automatic pilot' and then wonder why I } \\
\text { went there. }\end{array}$ & 4.9 & 5 & 0.1 \\
\hline I find myself preoccupied with the future or the past. & 2.1 & 3.2 & 1.1 \\
\hline I find myself doing things without paying attention. & 3.3 & 3.7 & 0.4 \\
\hline I snack without being aware that I'm eating. & 4.0 & 4.4 & 0.4 \\
\hline Totals & $\begin{array}{c}\text { Average Pretest } \\
\text { Score }\end{array}$ & $\begin{array}{c}\text { Average Post- } \\
\text { test Score }\end{array}$ & $\begin{array}{c}\text { Average In- } \\
\text { crease in Mind- } \\
\text { fulness }\end{array}$ \\
\hline & 3.5 & 4.0 & 0.5 \\
\hline
\end{tabular}

Using the posttest and pretest scores, the average increase in mindfulness was calculated. Pretest scores, posttest scores, and average change in mindfulness for each item are shown in Table 1. The overall average mindfulness improvement was then determined by averaging the net increase in mindfulness of each item. This overall average mindfulness point change for each item was found to be .5 , which is a large improvement considering the Likert scale for the Mindfulness Attention Awareness Scale (MAAS) ranges from 1 to 6, and selections are made in 1 point increments. Tables 2 and 3 detail the percent increase in memory and point increase in mindfulness for each participant in both groups. Meditation group participants experienced an average increase in mindfulness of .8, as opposed to .03 for control group participants (see Table 3). This data reveals that each experimental group participant experienced an increase in mindfulness as a result of daily meditation. In addition, the control group's small increase in mindfulness may reflect the participants' increased comfort with taking the MAAS rather than an actual increase in mindfulness. The control group allows the researcher to have higher confidence that mindfulness meditation was the sole cause of the increase in the meditation group's mindfulness scores.

In addition to the mindfulness survey, meditation group participants took a memory test before and after a week of mindfulness meditation. According to Table 2, this average gain in memory from before meditation to after meditation of $40.3 \%$ signifies that the meditation group experienced a statistically significant net increase in memory. Thus, it is evident that on average, mindfulness meditation improved the working memory capacity of meditation group participants.

Table 2: Percent Increase in Memory and Point Increase in Mindfulness For Each Meditation Group Participant and Total Averages for Meditation Group

\begin{tabular}{|c|c|c|c|}
\hline Participant \# & Percent Increase in Memory & Point Increase in Mindfulness & $\begin{array}{c}\text { Calculated Working } \\
\text { Memory \& Mindfulness } \\
\text { Increase }\end{array}$ \\
\hline 1 & $32.7 \%$ & 1.6 & Yes \\
\hline 2 & $11.4 \%$ & 2.1 & Yes \\
\hline
\end{tabular}




\begin{tabular}{|c|c|c|c|}
\hline 3 & $9.6 \%$ & 3.2 & Yes \\
\hline 4 & $11.0 \%$ & .1 & Yes \\
\hline 5 & $19.3 \%$ & .1 & Yes \\
\hline 6 & $66.7 \%$ & .1 & Yes \\
\hline 7 & $17.1 \%$ & 1.1 & Yes \\
\hline 8 & $41.2 \%$ & .9 & Yes \\
\hline 9 & $166.0 \%$ & .3 & Yes \\
\hline 10 & $35.0 \%$ & .1 & Yes \\
\hline 11 & $63.8 \%$ & .5 & Yes \\
\hline 12 & $102.4 \%$ & 1.1 & Yes \\
\hline 13 & $4.0 \%$ & .3 & Yes \\
\hline 14 & $15.3 \%$ & .3 & Yes \\
\hline 15 & $8.2 \%$ & .7 & Yes \\
\hline 16 & $117.4 \%$ & 1.9 & Yes \\
\hline 17 & $8.7 \%$ & .1 & Yes \\
\hline 18 & $25.6 \%$ & .2 & Yes \\
\hline 19 & $11.0 \%$ & .3 & Yes \\
\hline Totals & $\begin{array}{c}\text { Average Percent Increase in } \\
\text { Memory }\end{array}$ & $\begin{array}{l}\text { Average Point Increase in Mind- } \\
\text { fulness }\end{array}$ & \\
\hline & $40.3 \%$ & 0.8 & \\
\hline
\end{tabular}

For each meditation participant, their percent change in memory and the average change in mindfulness both increased. The research question that this study aimed to answer was: To what extent does a week of daily mindfulness meditation improve the working memory and mindfulness of teens in a Connecticut high school? The researcher hypothesized that a week of mindfulness meditation would increase both short term memory and mindfulness compared to the control group. The average increase in memory for each participant was $40.3 \%$ and the average point increase in mindfulness was 0.8 (see Table 2). Since both memory and mindfulness scores increased for each meditation participant, it is evident that there is a correlation between working memory capacity and one's mindfulness and thus, the original hypothesis is confirmed. 
Table 3: Percent Change in Memory and Point Change in Mindfulness for Each Running Control Group Participant and Total Averages for Control Group (Non-meditators)

\begin{tabular}{|c|c|c|c|}
\hline Participant \# & $\begin{array}{l}\text { Percent Change in } \\
\text { Memory }\end{array}$ & $\begin{array}{l}\text { Point Change in Mindful- } \\
\text { ness }\end{array}$ & $\begin{array}{l}\text { Calculated Working } \\
\text { Memory \& Mindfulness } \\
\text { Increase }\end{array}$ \\
\hline 20 & $-3 \%$ & .2 & No \\
\hline 21 & $-7 \%$ & .3 & No \\
\hline 22 & $-1 \%$ & -.2 & No \\
\hline 23 & $20 \%$ & -.1 & No \\
\hline 24 & $23 \%$ & -.3 & No \\
\hline 25 & $-23 \%$ & -.4 & No \\
\hline 26 & $45 \%$ & -.1 & No \\
\hline 27 & $-12 \%$ & .7 & No \\
\hline 28 & $-10 \%$ & -.2 & No \\
\hline 29 & $-42 \%$ & .3 & No \\
\hline 30 & $36 \%$ & -.2 & No \\
\hline 31 & $17 \%$ & -.1 & No \\
\hline 32 & $8 \%$ & -.2 & No \\
\hline 33 & $36 \%$ & -.1 & No \\
\hline 34 & $-3 \%$ & .8 & No \\
\hline 35 & $24 \%$ & -.4 & No \\
\hline 36 & $-17 \%$ & .6 & No \\
\hline 37 & $39 \%$ & -.1 & No \\
\hline \multirow[t]{2}{*}{$\begin{array}{l}\text { Totals For Con- } \\
\text { trol Group }\end{array}$} & $\begin{array}{c}\text { Average Percent Change in } \\
\text { Memory }\end{array}$ & $\begin{array}{l}\text { Average Point Change in Mind- } \\
\text { fulness }\end{array}$ & \\
\hline & $8.3 \%$ & .03 & \\
\hline
\end{tabular}


A study conducted by aforementioned Dianna Quach (2016), Professor of Professional Psychology at Alliant International University, investigated the connection between a short mindfulness intervention and working memory capacity, by comparing the memory score increases of Hatha yoga and mindfulness meditation groups. This study compared the memory score changes and mindfulness score changes of the mindfulness meditation group (see Table 2) with the running control group (see Table 3). While the mindfulness meditation group had an average percent increase of $40.3 \%$ in working memory capacity (WMC), the control group only experienced an $8.3 \%$ gain in WMC, which is consistent with prior findings (Alloyway 2016). This difference is also seen in the average point change in mindfulness, which was found to be 0.8 in the meditation group and 0.03 in the control group. By utilizing a control group, similar to Quach's design, the researcher was able to determine that the increases in both WMC and mindfulness were due to the mindfulness training and not due to repeating the test a second time with greater familiarity or effort. In addition, Quach examined middle school students in a large public southwestern middle school, while in this study, the researcher focused solely on a small sample of high school students. Quach and her team found that mindfulness meditation increased working memory capacity, which aligns with the results that this study found. This research addresses the gap in the current research of meditation's effects on high school students in particular and thus, builds on Quach's study as well as several others on the impact of mindfulness meditation on cognition and memory of adolescents.

One limitation of this study is the sample size was small, with only 37 participants. The researcher sent an email to the school to gather participants, yet it was difficult to get teenagers to meditate without incentive. It is impossible to know for sure if the participants were meditating, although, they all experienced a net increase in mindfulness from before to after a week, which is consistent with a week of daily mindfulness meditation.

These findings have implications on the future of mindfulness-based interventions in schools as now there is data to support that mindfulness meditation improves memory and mindfulness in high school students. Schools may decide to incorporate daily meditation into the school schedule, given its benefits on not only emotional development but on memory and thus, on academic success.

\section{Implications, Conclusions, and Future Research}

Now that the positive impact of mindfulness meditation on the mindfulness and working memory capacity of high school students has been established, there are multiple ways to utilize these findings to help high school students. The clearest way to utilize these findings is to implement mindfulness meditation programs in high schools across the country. There have been several schools that have started meditation programs and seen numerous benefits, such as reduced stress and anxiety and increased self-esteem (Waters, 2015). Now, these results serve to add to the gap in meditation research in teens and reflect that mindfulness meditation does, in fact, increase mindfulness and working memory capacity. Thus, this research simply adds another benefit for students to receive.

In most research studies, there are limitations to the new understanding due to the chosen method or the way the method was implemented. One limitation of this study is the small sample size of only 37 participants. To improve the reliability of the results, this study should be replicated with a larger pool of applicants. Future research should 
also include a more socioeconomically diverse population as research shows that those in lower socioeconomic classes, on average, score lower on tests of language and working memory capacity (Noble, 2005). This population of high socioeconomic class may have altered the results by having already high working memory capacity scores.

Another limitation could result from the timing of the study. The study was conducted in late February and early March, the middle of the third quarter of the school year, which is a very stressful time for many students. Many factors, such as cramming for AP Exams and standardized testing, and the start of spring sports, may have contributed to their higher stress levels. This may have impacted the mindfulness survey scores, as the stress levels of teens may have increased during their busy lives and had a mitigating effect on the positive implications of mindfulness meditation. Future studies should examine the differing effectiveness of meditation at different times of the year to determine whether differences in increases in mindfulness and memory scores are found.

Future research could go further in-depth on the impact of different types of meditations on mindfulness and working memory capacity in order to determine which one has the most statistically significant impact on teens, and thus, that could be used in school environments. Additionally, it may be beneficial to more fully examine the effects of meditation on the brain by using more sophisticated neurological tests, such as the Stroop task or the N-back. Finally, researchers could look into how mindfulness meditation affects one's grades, test scores, and other measures of school-related outcomes to help understand whether meditation improves school performance.

Although the aforementioned study conducted by Quach (2016) found that a short mindfulness meditation practice increased working memory capacity in a southwest United States middle school, this study is the first of its kind to provide support for the positive implications of mindfulness meditation on both mindfulness and working memory capacity in high school students.

\section{Acknowledgements}

This paper and the research behind it would not have been possible without the exceptional support of my advisor, Professor Michael Posner. His enthusiasm, knowledge and exacting attention to detail have been an inspiration and kept my work on track.

\section{References}

Alloway, R. G., Alloway, T. P., Magyari, P. M., \& Floyd, S. (2016). An exploratory study investigating the effects of barefoot running on working memory. Perceptual and motor skills, 122(2), 432-443.

Barnes, V. A., Treiber, F. A., \& Davis, H. (2001). Impact of transcendental meditation on cardiovascular function at rest and during acute stress in adolescents with high normal blood pressure. Journal of Psychosomatic Research, 51, 597-605.

Barnes, V. A., Bauza, L. B., \& Treiber, F. A. (2003). Impact of stress reduction on negative school behavior in adolescents. Health and Quality of Life Outcomes, 1(10). 
Beauchemin, J., Hutchins, T. L., \& Patterson, F. (2008). Mindfulness meditation may lessen anxiety, promote social skills, and improve academic performance among adolescents with learning disabilities. Complementary Health Practice Review, 13, 34-45.

Bethune, S. (2014). American Psychological Association survey shows teen stress rivals that of adults. American Psychological Association (202), 336-343. Chicago

Biegel, G. M., Brown, K. W., Shapiro, S. L., \& Schubert, C. M. (2009). Mindfulness-based stress reduction for the treatment of adolescent psychiatric outpatients: A randomized clinical trial. Journal of Consulting and Clinical Psychology, 77, 855-866.

Bluth, K., Campo, R. A., Pruteanu-Malinici, S., Reams, A., Mullarkey, M., \& Broderick, P. C. (2015). A school-based mindfulness pilot study for ethnically diverse at-risk adolescents. Mindfulness. Advance online publication. doi: 10.1007/s12671-014-0376-1

Brown, K. W., \& Ryan, R. M. (2003). The benefits of being present: mindfulness and its role in psychological well-being. Journal of personality and social psychology, 84(4), 822. Chicago

Butola, R., \& Chauhan, R. (2014). Effectiveness of Mindful Meditation on Attention, Short Term Memory and Visual Reaction Time on Normal Individual. Indian Journal of Physiotherapy and Occupational Therapy, 8(1), 149.

Buttle, H. (2011). Attention and Working Memory in Mindfulness-Meditation Practices. The Journal of Mind and Behavior, 123-134.

Campos, D., Cebolla, A., Quero, S., Bretón-López, J., Botella, C., Soler, J., ... \& Baños, R. M. (2016). Meditation and happiness: Mindfulness and self-compassion may mediate the meditation-happiness relationship. Personality and individual differences, 93, 80-85.

Davidson, R. J., Kabat-Zinn, J., Schumacher, J., Rosenkranz, M., Muller, D., Santorelli, S. F., ... \& Sheridan, J. F. (2003). Alterations in brain and immune function produced by mindfulness meditation. Psychosomatic medicine, 65(4), 564-570. Chicago

Davidson, R. J., Dunne, J., Eccles, J. S., Engle, A., Greenberg, M., Jennings, P., . . Vago, D. (2012). Contemplative practices and mental training: Prospects for American education. Child Development Perspectives, 6(2), 146-153.

Davis, D. M., \& Hayes, J. A. (2011). What are the benefits of mindfulness? A practice review of 
psychotherapy-related research. Psychotherapy, 48(2), 198. Chicago

Flook, L., Smalley, S. L., Kitil, M. J., Galla, B. M., Kaiser-Greenland, S., Locke, J., ... \& Kasari,

C. (2010). Effects of mindful awareness practices on executive functions in elementary school children. Journal of applied school psychology.

Flook, L., Goldberg, S. B., Pinger, L., \& Davidson, R. J. (2015). Promoting prosocial behavior and self-regulatory skills in preschool children through a mindfulness-based kindness curriculum. Developmental Psychology, 51(1), 44-51.

Greenberg, J., Romero, V. L., Elkin-Frankston, S., Bezdek, M. A., Schumacher, E. H., \& Lazar, S. W. (2019). Reduced interference in working memory following mindfulness training is associated with increases in hippocampal volume. Brain imaging and behavior, 13(2), 366-376.

Härkänen, T., Kuulasmaa, K., Sares-Jäske, L., Jousilahti, P., Peltonen, M., Borodulin, K., ... \& Koskinen, S. (2020). Estimating expected life-years and risk factor associations with mortality in Finland: cohort study. BMJ open, 10(3), e033741.

Human Benchmark Verbal Memory Test. Available online: http://www.humanbenchmark.com/tests/verbal-memory

Lazar, S. W., Kerr, C. E., Wasserman, R. H., Gray, J. R., Greve, D. N., Treadway, M. T., ... \& Rauch, S. L. (2005). Meditation experience is associated with increased cortical thickness. Neuroreport, 16(17), 1893.

Lyubomirsky, S., Sheldon, K. M., \& Schkade, D. (2005). Pursuing happiness: The architecture of sustainable change. Review of general psychology, 9(2), 111-131. Chicago

MacKillop, J., \& Anderson, E. J. (2007). Further psychometric validation of the mindful attention awareness scale (MAAS). Journal of Psychopathology and Behavioral Assessment, 29(4), 289-293.

MacLean, K. A., Ferrer, E., Aichele, S. R., Bridwell, D. A., Zanesco, A. P., Jacobs, T. L., . . .

Saron, C. D. (2010). Intensive meditation training improves perceptual discrimination and sustained attention. Psychological Science, 21, 829-839

Mrazek, M. D., Franklin, M. S., Phillips, D. T., Baird, B., \& Schooler, J. W. (2013). Mindfulness

Training Improves Working Memory Capacity and GRE Performance While Reducing Mind Wandering. Psychological Science, 24(5), 776-781. https://doi.org/10.1177/0956797612459659 
Noble K.G. Norman M.F. Farah M.J. Neurocognitive correlates of socioeconomic status in kindergarten children. Dev Sci. 2005; 8: 74-87

Ramesh, M., Sathian, B., Sinu, E., \& Kiranmai, S. R. (2013). Efficacy of rajayoga meditation on positive thinking: An index for self-satisfaction and happiness in life. Journal of clinical and diagnostic research: JCDR, 7(10), 2265.

Quach, D., Mano, K. E. J., \& Alexander, K. (2016). A randomized controlled trial examining the effect of mindfulness meditation on working memory capacity in adolescents. Journal of Adolescent Health, 58(5), 489-496.

Sedlmeier, P., Eberth, J., Schwarz, M., Zimmermann, D., Haarig, F., Jaeger, S., \& Kunze, S. (2012). The psychological effects of meditation: a meta-analysis. Psychological bulletin, 138(6), 1139.

Sevinc, G., Hölzel, B. K., Greenberg, J., Gard, T., Brunsch, V., Hashmi, J. A., ... \& Lazar, S. W. (2019). Strengthened Hippocampal Circuits Underlie Enhanced Retrieval of Extinguished Fear Memories Following Mindfulness Training. Biological Psychiatry.

Shoshani, A., \& Slone, M. (2013). Middle school transition from the strengths perspective:

Young adolescents' character strengths, subjective well-being, and school adjustment. Journal of Happiness Studies, 14(4), 1163-1181.

Stahl, J. E., Dossett, M. L., LaJoie, A. S., Denninger, J. W., Mehta, D. H., Goldman, R., ... \&

Benson, H. (2015). Relaxation response and resiliency training and its effect on healthcare resource utilization. PloS one, 10(10). Chicago

Taylor, V. A., Grant, J., Daneault, V., Scavone, G., Breton, E., Roffe-Vidal, S., ... \& Beauregard, M. (2011). Impact of mindfulness on the neural responses to emotional pictures in experienced and beginner meditators. Neuroimage, 57(4), 1524-1533.

Tenney, Y. J., Diller, D. E., Deutsch, S., \& Godfrey, K. (2006). The AMBR Experiments: Methodology and Human Benchmark Results. In Modeling Human Behavior With Integrated Cognitive Architectures (pp. 31-62). Psychology Press.

Van Vugt, M. K., \& Jha, A. P. (2011). Investigating the impact of mindfulness meditation training on working memory: A mathematical modeling approach. Cognitive, Affective, \& Behavioral Neuroscience, 11(3), 344-353.

Viafora, D. P., Mathiesen, S. G., \& Unsworth, S. J. (2015). Teaching mindfulness to middle 
school students and homeless youth in school classrooms. Journal of Child and Family Studies, 24(5), 1179-1191.

Waters, L., Barsky, A., Ridd, A., \& Allen, K. (2015). Contemplative education: A systematic,

evidence-based review of the effect of meditation interventions in schools. Educational Psychology Review, 27(1), 103-134.

Wynne, A. (2007). The origin of Buddhist meditation. Routledge.

Zylowska, L., Ackerman, D. L., Yang, M. H., Futrell, J. L., Horton, N. L., Hale, T. S., ... \&

Smalley, S. L. (2008). Mindfulness meditation training in adults and adolescents with ADHD: A feasibility study. Journal of attention disorders, 11(6), 737-746. 